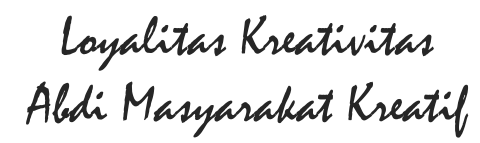

Loyalitas Kreativitas

Aldi Masyarakat Kreatif

P-ISSN 2722-2101, E-ISSN 2722-4201

Program Studi Ekonomi Manajemen Universitas Pamulang

Jurnal LOKABMAS Kreatif Vol. 01, No. 02, Hal. 11-15

Email:jurnalkreatif.manajemen@gmail.com

\title{
PENGARUH COMMUNITY OF PRACTICE PADA IMPLEMENTASI KNOWLEDGE MANAGEMENT PADA KANTOR KELURAHAN REMPOA
}

\author{
Risza Putri Elburdah, Bulan Oktrima, Supardi, Styo Budi Utomo, \\ Hestu Nugroho warasto
}

Dosen Ekonomi Fakultas Ekonomi Universitas Pamulang

Email dosen01022@unpam.ac.id, dosen00491@unpam.ac.id, dosen01848@unpam.ac.id

\begin{abstract}
ABSTRAK
Tujuan dari Kegiatan Pengabdian Kepada Masyarakat adalah untuk melaksanakan salah satu Tri Dharma Perguruan Tinggi. Selain itu diharapkan dengan pengabdian kepada masyarakat tersebut keberadaan perguruan tinggi dapat memberikan kontribusi besar kepada pengembangan dan penerapan keilmuan kepada masyarakat.

Metode pelaksanaan pengabdian ini dilakukan dalam beberapa kegiatan yaitu tahap survei yaitu sosialisasi dilakukan dengan menyusun berbagai hal yang akan disampaikan pada saat kegiatan pengabdian yang akan dilakukan yang meliputi: penyusunan materi yang akan diberikan, penyusunan jadwal pemberian materi, pembagian tugas tim pengabdian dan survei ke lokasi pengabdian. Tahap sosialisasi yaitu sebelum kegiatan pengabdian dilaksanakan terlebih dahulu dilakukan tahap sosialisasi yaitu melakukan silaturahmi dengan Kepala Kantor Kelurahan, menyampaikan maksud dan tujuan pengabdian ini. Pada tahap ini juga dilakukan jalinan kerjasama dan menentukan jadwal kegiatan pengabdian. Tim pelaksana kegiatan pengabdian pada masyarakat adalah dosen Fakultas Ekonomi jurusan manajemen sebanyak 5 orang. Tim pengabdian memberikan materi tentang Pengaruh Community of Practice Pada Implementasi Knowledge Management di kantor Kelurahan Rempoa.

Hasil pengabdian masyarakat yang diperoleh adalah terbentuknya Community of Practice pada kantor Kelurahan Rempoa yang dapat digunakan sebagai salah satu media dalam manajemen pengetahuan. Ilmu yang diperoleh pada Pengabdian Masyarakat kali ini diharapkan mampu memberikan semangat baru bagi kita dalam menyampaikan materi dan motivasi serta berkontribusi bagi kantor kelurahan rempoa
\end{abstract}

\section{Kata Kunci: Community of Practice, Knowledge Management}

\begin{abstract}
ABSTRAC
The purpose of community service is to implement one of Tri Dharma colleges. In addition, it is expected that with devotion to the community the existence of universities can contribute greatly to the development and application of scholarly to the community.

This method of devotion implementation is done in several activities namely the survey stage that is socialization is done by arranging various things to be delivered during the dedication activities that will be conducted which include: the preparation of materials that will be given, drafting the awarding schedule, the division of tasks of devotion teams and surveys to the location of devotion. Socialization stage is before the dedication activities carried out first conducted socialization stage is doing a relationship with the chief, convey the intent and purpose of this devotion. At this stage is also done cooperation and determine the schedule of the dedication activities. The team of community dedication activities is the Faculty of Economics lecturer in management as many as 5 people. The dedication team provides material about patchwork The Influence of Community of Practice on the implementation of Knowledge Management at Kantor Kelurahan Rempoa.
\end{abstract}




\section{Loyalitas Kreativitas \\ Aldi Masyarakat Kreatif}

P-ISSN 2722-2101, E-ISSN 2722-4201

Program Studi Ekonomi Manajemen Universitas Pamulang Jurnal LOKABMAS Kreatif Vol. 01, No. 02, Hal. 11-15

Email:jurnalkreatif.manajemen@gmail.com

The results obtained community service is the formation of Community of Practice on Kantor Kelurahan Rempoa that can be used as one of the media in knowledge management. The knowledge gained at Community Service this time is expected to be able to provide new enthusiasm for us in delivering material and motivation as well as contributing.

\section{Keywords: Community of Practice, Knowledge Management}

\section{PENDAHULUAN}

Munculnya ekonomi berbasis pengetahuan (knowledge-based economy), memaksa organisasi untuk meninggalkan perspektif tradisional dan mengadopsi pendekatan manajemen pengetahuan (Trivellas et al., 2015:239). Knowledge telah menjadi aset kunci bagi organisasi untuk dapat menghasilkan keunggulan kompetitif yang berkelanjutan. Knowledge management berfokus pada identifikasi, berbagi, membuat dan menyimpan pengetahuan dalam rangka pelaksanaan pembelajaran organisasi.

Knowledge management terdiri dari dua jenis pengetahuan: explicit knowledge, pengetahuan yang dapat dipelajari secara jelas dalam bentuk tetulis dan lisan, seperti prosedur, peraturan, dan kebijakan, dan tacit knowledge, pengetahuan yang sifatnya melekat dalam tiap individu seperti, nilainilai, keyakinan karyawan, pengalaman, dan pengetahuan knowhow. Pengetahuan adalah pengalaman terstruktur, nilai, informasi kontekstual dan wawasan pakar yang menyediakan kerangka kerja untuk mengevaluasi dan menggabungkan pengalamaan dan pengetahuan baru yang menghasilkan tindakan serta menghasilkan keputusan yang lebih baik dan menghasilkan input yang efektif pada dialog dan kreativitas organisasi.

Kota Tangerang Selatan merupakan daerah otonom yang terbentuk pada akhir tahun 2008 berdasarkan Undang-undang Nomor 51 Tahun 2008 tentang Pembentukan Kota Tangerang Selatan di Propinsi Banten tertanggal 26 November 2008. Pembentukan daerah otonom baru tersebut, yang merupakan pemekaran dari Kabupaten Tangerang, dilakukan dengan tujuan meningkatkan pelayanan dalam bidang pemerintahan, pembangunan, dan kemasyarakatan serta dapat memberikan kemampuan

dalam pemanfaatan potensi daerah. Untuk meningkatkan pelayanan kepada masyarakat para pegawai kelurahan perlu memetakan dan mengetahui pengetahuan-pengetahuan apa saja yang ada pada setiap pegawai. Hal ini bertujuan agar pengetahuan - pengetahuan tersebut tidak hilang apabila pegawai tersebut memasuki pensiun atau dipindahtugaskan ke kantor kelurahan wilayah lain.

Pengetahuan adalah segala sesuatu yang diketahui dan pernah dipelajari dari lingkungan sekitar. Hal ini dapat meliputi mata pelajaran, tradisi, informasi dan keterampilan. Semakin sering manusia belajar, berfikir dan bertanya, semakin bertambah pula pengetahuan yang dimilikinya. Pengetahuan sangat bermanfaat bagi kehidupan manusia baik pada masa sekarang maupun masa depan. Hal itu berarti pengetahuan menjadi faktor penting bagi seseorang maupun organisasi untuk dapat bersaing di lingkungan yang semakin kompetitif.

Setiap individu harus tahu bagaimana cara memanfaatkanpengetahuan untuk meningkatkan keunggulan kompetitif bagi dirinya sendiri maupun orang lain. Organisasi harus mampu memanfaatkan kekuatan dan peluang serta memahami kelemahan dan ancaman agar mampu bertahan dalam persaingan. Untuk melakukan pemanfaatan dan pengembangan pengetahuan, diperlukan pengelolaan dengan aktivitas berbagi pengetahuan.

Manfaat adanya berbagi pengetahuanadalah terciptanya pengetahuan baru yang dapat menghasilkan inovasi, meningkatkan keterampilan setiap anggotanya dan mengurangi resiko terulang kembali kesalahan yang pernah dilakukan.Pelaksanaan kegiatan ini tidak mudah dilakukan, mengingat adanya karyawan yang berfikir ingin menyimpan pengetahuan yang dimiliki untuk dirinya sendiri. Mereka akan merasa terancam jika orang lain mengetahui pengetahuan yang lebih banyak dari dirinya, sehingga dapat menimbulkan persaingan yang tidak sehat. 


\section{Loyalitas Kreativitas \\ Aldi Masyarakat Kreatif}

P-ISSN 2722-2101, E-ISSN 2722-4201

Program Studi Ekonomi Manajemen Universitas Pamulang Jurnal LOKABMAS Kreatif Vol. 01, No. 02, Hal. 11-15

Email:jurnalkreatif.manajemen@gmail.com
Menurut Triana dkk (2016) berbagi pengetahuan merupakan proses yang sistematis dalam penyampaian pesan antar individu maupun organisasi melalui media yang beragam. Setiap individu berhak menentukan media apa yang akan mereka pakai untuk melakukan berbagi pengetahuan, yang terpenting adalah penerima pesan mampu memahami apa yang telah disampaikan. Salah satu media untuk berbagi ini adalah community of practice atau COP.Adanya COP ini akan membantu para pegawai untuk berbagi pengetahuan dan pengalaman yang dimilikinyaagar bisa menjadi pengathuan baru bagi pegawai lainnya. COP merupakan wadah berbagi dengan konsep yang mampu membuat pegawai yang sungkan berbagi menjadi lebih terbuka. Solusi dari pengabdian kepada masyarakat ini adalah terbentuknya COP pada kantor kelurahan Rempoa.

\section{RUMUSAN MASALAH}

Dengan mempertimbangkan latar belakang yang telah dijelaskan diatas kami berinisiatif untuk melakukan pengabdian masyarakat bagi pegawai Kantor Kelurahan Rempoas khususnya dalam program pelatihan pembentukan Community of Practice ( $\mathrm{CoP})$.

TUJUAN PELAKSANAAN

1. Memberikan pengetahuan kepada pegawai Kantor Kelurahan Rempoa mengenai $\mathrm{CoP}$ dan Knowledge Management.

2. Membentuk CoP dalam implementasi dalam perilaku pegawai Kantor Kelurahan Rempoa.

\section{TINJAUAN PUSTAKA}

Pengetahuan adalah aset tidak berwujud yang hampir tidak mungkin untuk ditiru dan dipandang sebagai instrumen kompetitif yang harus dikelola secara efektif oleh setiap organisasi. Meskipun banyak yang telah membahas pentingnya pengetahuan dalam sebuah manajemen, tetapi relatif sedikit yang memperhatikan bagaimana proses pembuatan dan pengelolaan pengetahuan.

Dalam proses pembuatan pengetahuan ini, kemudian dapat ditarik perbedaan pengetahuan menjadi dua kategori yaitu, pengetahuan tacit dan pengetahuan ekplisit. Pengetahuan tacit merupakan pengetahuan yang ada di dalam pikiran setiap individu sesuai dengan pemahaman, keahlian, dan pengalaman seseorang. Pengetahuan tacit merupakan pengetahuan yang sulit untuk diformulasikan dan dikomunikasikan, karena berada di dalam benak masing - masing orang.

Pengetahuan yang ada dalam diri seseorang, tampak seperti sebuah gunung es. Berdasarkan pengertiannya, maka pengetahuan tacit dapat dikategorikan sebagai pengetahuan personal. Alavi (2001) mengungkapkan, eksplisit dimensi pengetahuan (selanjutnya disebut sebagai pengetahuan eksplisit) diartikulasikan, dikodifikasi, dan dikomunikasikan dalam bentuk simbolik dan/atau bahasa alami. Contohnya pembelian sebuah produk elektronik, pasti disertai petunjuk pemakaian. Petunjuk pemakaian itu merupakan pengetahuan seputar pengoperasian produk tersebut.

Penerapan pengetahuan eksplisit lebih mudah, karena pengetahuan yang diperoleh dalam bentuk tulisan atau rekaman yang telah didokumentasikan, sehingga karyawan dapat mempelajarinya secara mandiri. Pengetahuan eksplisit dalam penelitian ini adalah prosedur kerja dan teknologi. Prosedur kerja adalah tugas dan tanggung jawab yang telah diberikan kepada karyawan yang bersifat formal. Pengetahuan eksplisit ditandai, menurut berbagai penelitian, dengan kemampuannya untuk dinyatakan sebagai kata atau nomor, dalam bentuk data tercetak, formula ilmiah, manual, file komputer, dokumen, paten, dan prosedur standar atau titik awal universal yang dapat dengan mudah ditransfer dan disebarkan.)

Pengetahuan adalah proses, maka secara tersirat fokus manajemen adalah pada aliran pengetahuan dan proses penciptaan, berbagi, dan distribusi pengetahuan" (Alavi \& Leidner, 200;Sundiman \& Idrus, 2015).

Disinilah peran penting dari teknologi informasi, mengingat canggihnyateknologi saat ini. Misalnya, internet, intranet, browser, extranet, data mining teknik, gudang data, dan agen software. Bagian terpenting dalam knowledge management adalah mendorong individu-individu dalam organisasi untuk 


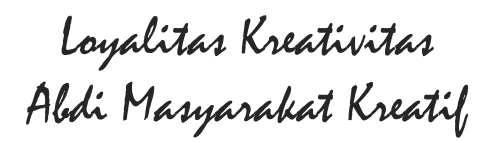

melakukan knowledge sharing. Knowledge sharing berperan dalam penciptaan tacit knowledge yang berkaitan dengan pekerjaan di antara anggota organisasi. Mengingat bahwa knowledge sharing meliputi kegiatan karyawan untuk berbagi pengetahan dengan orang lain, dan perilaku mereka dalam bertukar informasi yang relevan dengan rekan kerja di seluruh organisasi. Permasalahan manajemen yang sering terjadi justru karena kurangnya informasi yang diperlukan karyawan untuk menjalankan tugasnya. Penerapan knowledge sharing diharapkan dapat memenuhi kebutuhan informasi dan pengetahuan karyawan agar dapat menjalankan tugasnya dengan baik.

Penelitian yang dilakukan oleh Rudiyanto (2012) mengungkapkan bahwa knowledge sharing berpengaruh signifikan terhadap kinerja karyawan. Di sisi lain, penelitian yang dilakukan oleh Wang etal. (2016) menunjukkan bahwa knowledge sharing tidak berpengaruh langsung pada kinerja karyawan, tetapi di mediasi oleh variabel innovation capability dan intellectual capital. Pengetahuan yang didapat individu dalam organisasi akan bertambah dengan adanya knowledge sharing. mengemukakan bahwa kemampuan potensi (IQ) dan kemampuan reality (knowledge and skill) merupakan faktor yang mempengaruhi kinerja karyawan. Knowledge atau pengetahuan sangat penting bagi setiap karyawan dalam menjalankan tugas, karena dengan tertanamnya pengetahuan pada setiap karyawan, maka karyawan tersebut dapat menjalankan tugasnya masing-masing sesuai dengan yang diharapkan organisasi, sehingga akan berdampak baik pada kinerja karyawan tersebut.

Knowledge sharing adalah proses sistematis dalam berbagi, dan mendistibusikan pengetahuan dari satu pihak ke pihak lain yang membutuhkan, melalui metode dan media yang bermacam-macam, pada PKM kali ini media yang dipilih adalah Community of Practice atau COP. Knowledge sharing yang terjadi dalam organisasi dapat dibedakan menjadi dua, yaitu tacit knowledge sharing dan explicit knowledge sharing: 1. Tacit Knowledge Sharing Tacit knowledge bersifat personal, dikembangkan melalui pengalaman dan sulit untuk dikomunikasikan. Tacit knowledge dikategorikan sebagai pengetahuan yang diperoleh dari pengalaman individu atau perorangan. Pengalaman yang diperoleh tiap individu dalam organisasi dapat berbeda-beda berdasarkan keadaan yang tak dapat diprediksi. 2.Explicit Knowledge Sharing Explicit knowledge merupakan pengetahuan yang dapat dipelajari dan dikomunikasikan dengan mudah, dalam bentuk lisan maupun tertulis. Explicit knowledge bersifat sistematis sehingga mudah untuk dibagikan.

\section{HASIL DAN PEMBAHASAN}

Kegiatan Pengabdian Masyarakat Universitas Pamulang yang dilakukan oleh dosen-dosen program studi Manajemen telah berjalan dengan lancar dan mendapat sambutan hangat dari tempat pelaksanaan kegiatan ini yaitu di Kantor Kelurahan Rempoa .

Berdasarkan hasil tahapan solusi yang diberikan, saat ini Kantor kelurahan Rempoa sedang menyusun struktur kepengurusan untuk pembentukan Community of Practice (CoP). Istilah $C o P$ cukup asing bagi pegawai kantor Kelurahan Rempoa, namun setelah dijelaskan bahwa media ini hampir serupa dengan penyelenggaraan rapat, yang membedakan adalah suasana yang dibangun harus menyenangkan. Suasana nyaman ini yang diharapkan dapat membuat semua peserta terlibat aktif dalam proses transfer knowledge.

Knowledge sharing berperan dalam penciptaan tacit knowledge yang berkaitan dengan pekerjaan di antara anggota organisasi. Mengingat bahwa knowledge sharing meliputi kegiatan karyawan untuk berbagi pengetahan dengan orang lain, dan perilaku mereka dalam bertukar informasi yang relevan dengan rekan kerja di seluruh organisasi. Permasalahan manajemen yang sering terjadi justru karena kurangnya informasi yang diperlukan karyawan untuk menjalankan tugasnya. Penerapan knowledge sharing diharapkan dapat memenuhi kebutuhan informasi dan pengetahuan karyawan agar dapat menjalankan tugasnya dengan baik. Solusi yang akan diberikan untuk Kantor Kelurahan Rempoa adalah:

1.Memetakan kompetensi individu yang menjadi penunjuang utama pelaksanaan 


\section{Loyalitas Kreativitas \\ Aldi Masyarakat Kreatif}

P-ISSN 2722-2101, E-ISSN 2722-4201

Program Studi Ekonomi Manajemen Universitas Pamulang Jurnal LOKABMAS Kreatif Vol. 01, No. 02, Hal. 11-15

Email:jurnalkreatif.manajemen@gmail.com pelayanan pada Kantor Kelurahan Rempoa, keluaran kegiatan ini adalah peta jabatan. Hal ini dilakukan untuk melihat sikap pegawai dalam kesiapan untuk berbagi. Sikap adalah perwujudan pikiran evaluasi

tentang sebuah obyek, manusia atau peristiwa, baik yang diinginkan atau yang tidak diinginkan (Widyasari, 2013). Sikap yang kuat akan menghasilkan sesuatu sesuai dengan tekad. Hal ini berarti jika karyawan menganggap budaya yang ada dalam organisasi sesuai dengan keinginannya, mereka akan memberikan sikap positif dan mendukung organisasi dalam mencapai tujuan. Sebaliknya, karyawan akan bersikap negatif dan acuh terhadap kemajuan organisasi jika budaya yang ada tidak sesuai dengan keinginannya. Oleh karena itu, organisasi perlu melakukan upayaupaya untuk meningkatkan kesadaran karyawan melakukan berbagi pengetahuan.Sikap karyawan yang mendukung proses berbagi pengetahuansangat dibutuhkan, karena hal tersebutmerupakan upaya untuk menciptakan ide-ide baru, meningkatkan produktivitas dan mencapai visi, misi serta tujuan organisasi. 2. Membentuk media berbagi pengetahuan, keluaran kegiatan ini adalah $C O P$ kantor keluarahan Rempoa. Membagikan pengetahuan dari tacit ke ekspilisit salah satunya dengan Community of Practice ( $\mathrm{CoP}$ ). Community of Practice atau lebih dikenal dengan CoP merupakan kumpulan orang-orang dalam lingkungan yang sama atau komunitas yang sama yang mempunyai dasar pemikiran yang sama untuk saling berbagi.

\section{KESIMPULAN DAN SARAN \\ Kesimpulan}

Kantor kelurahan Rempoa sampai saat ini belum memiliki wadah khusus untuk berbagi pengetahuan. Para pegawai mengaku mereka hanya menggunakan waktu meeting untuk membicarakan permasalahan khusus, namun tidak mengarah pada mempertahankan aset yang dimiliki.

Kualitas pengetahuan sumber daya manusia pegawai Kantor Kelurahan Rempoa mampu menciptakan fleksibilitas dan perencanaan yang lebih baik, kemampuan penyelesaian masalah akan meningkatkan kinerja kantor Kelurahan dalam kualitas pelayanan dan kepuasan dalam melayani masyarakat.

\section{Saran}

Pada dasarnya kinerja merupakan sesuatu hal yang bersifat individual, karena setiap karyawan memiliki tingkat kemampuan yang berbeda-beda. Oleh karena itu adanya COP, sebaiknya harus dilengkapi champion atau orang-orang yang mampu menjaga semangat berbagi pengetahuan ini terus dilakukan

\section{DAFTAR PUSTAKA}

Rudiyanto, Hendri. 2012. Pengaruh Knowledge Sharing Terhadap Kinerja Staf Administrasi PT. Guna Layan Kuasa (Gulaku) Kantor Pusat Jakarta. Skripsi Fakultas Ilmu Sosial dan Ilmu Politik. Universitas Indonesia.

Triana, A., Utami, H. N., \& Ruhana, I. (2016). Pengaruh Komunikasi Organisasi Terhadap Berbagi Pengetahuan dan Kinerja Karyawan (Studi pada Karyawan Hotel Gajah Mada Graha Malang). Jurnal Administrasi Bisnis, 35(2), 86-93.

Trivellas, P., Akrivouli, Z., Tsifora, E., Tsoutsa, P. 2015. The Impact of Knowledge Sharing Culture on job Satisfaction in Accounting Firm with Mediating Effect of general Competencies. E-journal Procedia Economic and Finance Elsevier. 19: 238-247

Pasaribu, V. L. D., Agrasadya, A., Shabrina, N., \& Krisnaldy, K. (2020). MENJADI ENTERPRENEUR MUDA YANG MEMILIKI JIWA LEADERSHIP UNTUK MENGHADAPI MASA DEPAN. Abdi Laksana, 1(1)

Pasaribu, V. L. D., Elburdah, R. P., Sudarso, E., \& Fauziah, G. (2020). PENGGUNAAN MANAJEMEN WAKTU TERHADAP PENINGKATAN PRESTASI BELAJAR DI SMP ARAISIYAH. Jurnal ABDIMAS, 1(1) 


\section{Loyalitas Kreativitas \\ Aldi Masyarakat Kreatif}

P-ISSN 2722-2101, E-ISSN 2722-4201

Program Studi Ekonomi Manajemen Universitas Pamulang Jurnal LOKABMAS Kreatif Vol. 01, No. 02, Hal. 11-15

Email:jurnalkreatif.manajemen@gmail.com

Pasaribu, V. L. D., Susanti, F., \& Hartuti, E. T. K. (2019). MEMOTIVASI SISWA DAN SISWI SMK LETRIS INDONESIA DI DALAM MENENTUKAN PILIHAN UNTUK MELANJUTKAN PENDIDIKAN ATAU BEKERJA SETELAH LULUS SEKOLAH. Jurnal Pengabdian Dharma Laksana, 1(2), 161-172.

Pasaribu, V. L. D., Oktrima, B., Prabowo, B., Arianto, N., \& Haryoko, U. B. (2020). PROGAM PENDAMPINGAN DAN

PENYELENGGARAAN PENDIDIKAN ANAK PADA USIA DINI TERHADAP PRESTASI BELAJAR DILINGKUNGAN RT 020 RW 009. KEL GIRI PENI. KEC WATES. YOGYAKARTA. JURNAL LOKABMAS KREATIF, 1(1), 71-75.

Pasaribu, V. L. D., Sulaiman, S., Sutiman, S., Thaharudin, T., \& Purnomo, B. Y. (2020). PENGENALAN LETAK POSYANDU TERDEKAT DIKELURAHAN PISANGAN DENGAN MANAJEMEN PEMASARAN REVOLUSI 4.0 UNTUK MENINGKATKAN PENGETAHUAN MASYARAKAT LETAK DAN FUNGSI POSYANDU TERDEKAT PADA KELURAHAN PISANGAN. DEDIKASI PKM, 1(1), 105-110.

Pasaribu, V. L. D., \& Krisnaldy, K. (2019). Manajemen Risiko dan Asuransi.

Wang, Zhining, Sharma, P.N., Cao, J. 2016. From Knowledge Sharing to Firm Performance: A Predictive Model Comparison. Journal of Business Research. Elsevier. 69: 4650-4658.
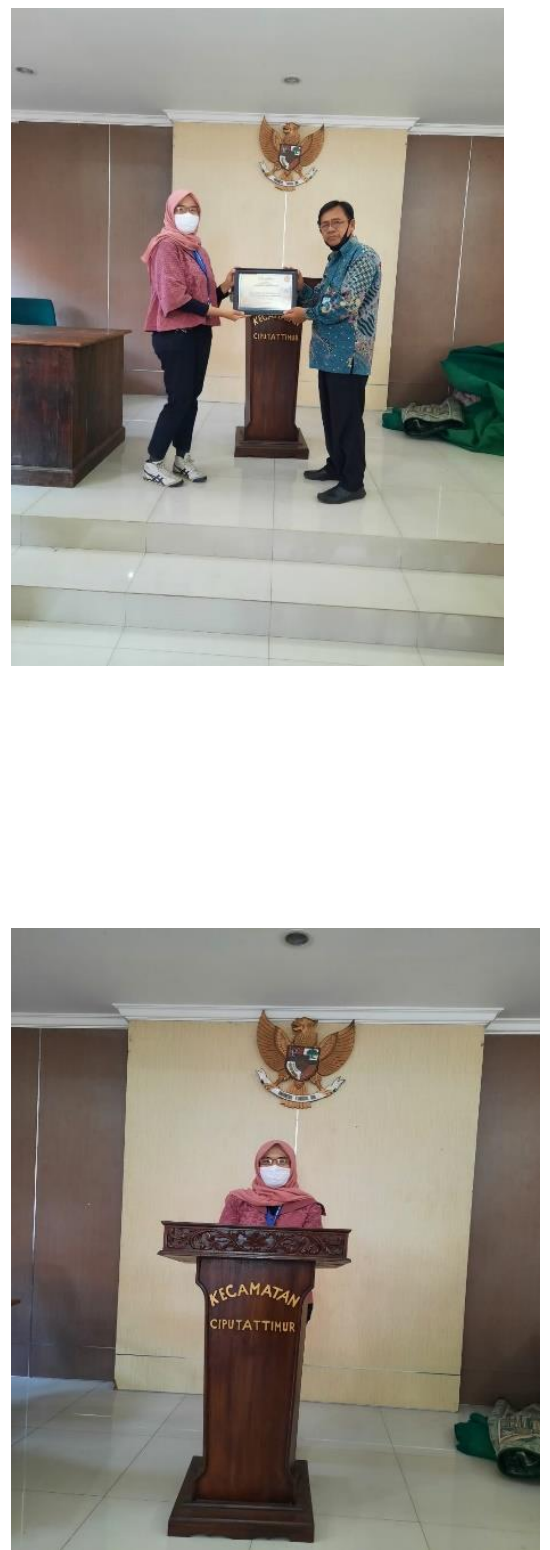

\section{DOKUMENTASI KEGIATAN}

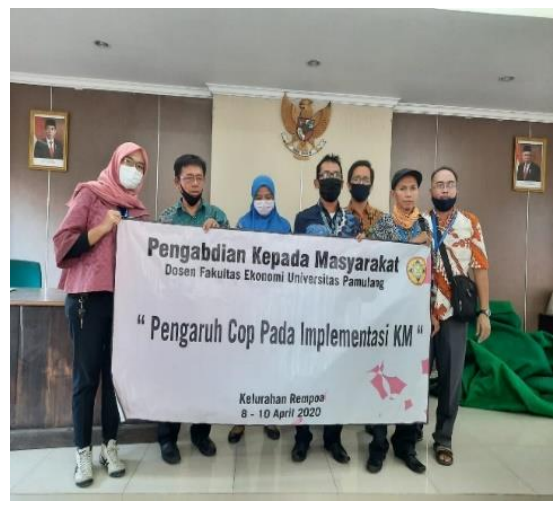

